\title{
Design da Informação e Design de Identidade: busca por convergência para a construção de espaços sensoriais demarca.
} Information Design and Identity Design: search for convergence for the construction of brand sensorial spaces.

\author{
João Raposo \& Monica Moura
}

Design Contemporâneo, Design da Informação, Design de Identidade, Marca

\begin{abstract}
Na contemporaneidade as marcas extrapolam a área comercial e vão além dos produtos para envolver as pessoas de forma significativacom seu universo simbólico. Usam para isto os estímulos sensoriais relacionados a sua personalidade e incluem elementos característicos do universo da experiência. $O$ Design de Informação constrói abordagens que consideram a percepção da informação, a geração de conhecimento e informação para a comunicação, sistemas de visualização, entre outros. O Design de Identidade de Marca é a expressão visual e verbal da marca, através dela podemos vê-la, tocá-la, agarrála e ouvi-la. Alguns dos sistemas de Identidade de Marca são desenvolvidos de maneira a se tornarem memoráveis e diferenciados. É na loja-conceito que ocorre a representação máxima da marca e seus conceitos estão estampados em todos os seus pontos de contato. Este artigo procura construir relações entre o Design da Informação e o Design de Identidade ao enumerar os conceitos de cada área e encontrar pontos convergentes que facilitem a percepção de uma marca dentro do ponto de venda na contemporaneidade.
\end{abstract}

\section{Contemporary Design, Information Design, Identity Design, Brand}

In contemporary times brands extend beyond the commercial area and go beyond products to involve people in a significant way with their symbolic universe. They use sensory stimuli related to their personality and include elements characteristic of the universe of experience. Information Design builds approaches that consider the perception of information, the generation of knowledge and information for communication, visualization systems, among others. Brand ldentity Design is the visual and verbal expression of the brand, through it we can see it, touch it, grasp it and listen to it. Some of the Brand Identity systems are developed to be memorable and differentiated. It is in the concept store that the maximum representation of the brand takes place and its concepts are printed in all its points of contact. This article seeks to build relationships between Information Design and Identity Design by enumerating the concepts of each area and finding convergent points that facilitate the perception of a brand within the point of sale in the contemporary world.

\section{Introdução}

Ao longo do tempo as marcas ultrapassaram seu universo comercial e adquiriram dimensões sociais, buscando envolver as pessoas com estímulos sensoriais associadosà sua personalidade. Isso pode acontecer nos projetos de ambientes, da identidade olfativa, das cores, imagens e iluminação. Logo, as marcas, precisam incorporar elementos do universo da experiência e da sensorialidade, para transmitir seus valores. Com a variedade de produtos e canais de compra disponíveis, o consumidor se torna mais exigente e quer que suas necessidades de consumo sejam atendidas com produtos e serviços com os quais ele se identifique.

Através do Design de Informação é possível construir abordagens que consideram a percepção da informação, a geração de conhecimento para a aprendizagem, sistemas de visualização e organização de dados em interfaces correlacionados a infografia, entre outros. A Sociedade Brasileira de Design da Informação - SBDI, define como a área do Design Gráfico que objetiva equacionar os aspectos sintáticos, semânticos e pragmáticos que envolvem os

Anais do 9 $\mathrm{CIDI}$ e 9 CONGIC

Luciane Maria Fadel, Carla Spinillo, Anderson

Horta, Cristina Portugal (orgs.)

Sociedade Brasileira de Design da Informação - SBDI

Belo Horizonte | Brasil | 2019

ISBN 978-85-212-1728-2
Proceedings of the 9th CIDI and 9th CONGIC

Luciane Maria Fadel, Carla Spinillo, Anderson Horta, Cristina Portugal (orgs.)

Sociedade Brasileira de Design da Informação - SBDI Belo Horizonte | Brazil | 2019

ISBN 978-85-212-1728-2 
sistemas de informação através da contextualização, planejamento, produção e interface gráfica da informação junto ao seu público alvo. Em resumo, trata-se de organizar e apresentar informações de maneira atrativa e eficaz para a construção de sentido e valor. Logo, o principal objetivo do Design da Informação é a clareza da comunicação.

Fazera relação entre o Design da Informação e o Design de Identidade de Marca é o objetivo desse artigo, nele buscaremos relacionar os conceitos de cada área e encontrar pontos convergentes que facilitem a percepção de uma marca dentro do seu espaço de venda, considerando ospreceitos de cada um, estabelecendo uma relação que possa ser usada em projetos de lojas conceito.

Segundo Plascak (2008), é nas lojas conceito que acontece relação da marca com as pessoas, através da estimulação de todos os sentidos.Aautora nos diz que "este é oespaçosensorial da marca, onde todas as suas manifestações falam a mesma língua e permitem uma relação direta com o cliente" (Plascak, 2008, p. 5). São os locais onde ocorrem a representação máxima da identidade da marca e onde seus conceitos estão estampados em todas as suas possibilidades. Marcas que constroem vínculos sólidos com seus consumidores tendem a ser preferidas, pois apesar de comprarmos produtos, queremos receber experiências traduzidaspor um discurso sedutor.

A abordagem metodológica adotada será a revisão bibliográfica e o estudo de caso. Santos aponta que a revisão bibliográfica é importante face ao "volume crescente de conhecimento acumulado gerado ao redor do globo nas mais diferentes temáticas" (Santos, 2018, p. 45). Além disso, adotaremos o estudo de caso para verificar a existência ou a carência da aplicação das relações do design da informação e o de identidade de marca.

\section{0 comportamento do consumidor moderno}

Kotler (1974), afirma que as decisões de compra nãosão influenciadas apenas pelos produtos tangíveis ou serviços oferecidos. As pessoas respondem ao produto total, o que inclui serviços, embalagens, imagens e outras caracteristicas que o acompanham. Uma das mais importantes é o local onde o produto ou serviço é consumido, em alguns casos aatmosfera deste local se torna mais importante que o próprio produto, convertendo-se no produto principal.

O conceito de criar ambientes artificiais atraentes pode ser relacionado aos templos gregos, catedrais medievais e paláciosrenacentistas, pois essessão exemplos de que o homem sempre buscou adornar suas edificações com poderosos significados sociais e estéticos. Do mesmo modo as lojas podem ser desenhadas para despertar sentimentos nos compradores, produzindoefeitos emocionais específicos, que associados à marca possam se converter em experiências de compra que contabilizem a favor dela.

Para Lipovetsky (2016), estamos numa era em que o comprador se tornou um "colecionador de experiências", buscando novas sensações e emotividades. Ouseja uma vez saciadas as necessidades básicas, o consumidor é cada vez mais comandado pelas emoções, pelo desejo de viver experiênciasagradáveis, de fruir bens de qualidade sensitiva, simbólica e estética. Os espaços comerciais são concebidos para transmitir uma mensagem coerente que se manifesta da vitrine à decoração, do mobiliárioaolayout do espaço, tudo isso organizado para traduzir a essência da marca e gerar interações inspiradoras e coerentes com o seu propósito.

Helmefalke Hultén (2017) apresentam o conceito de sinais multissensoriais, quedefinem como aqueles que complementam a visão nointerior da loja, como um perfume ou uma música. Como os estímulos visuais são os mais comuns, os varejistas deveriam complementar a atmosfera da loja com sensações auditivas, gustativas, hápticas ou olfativas, de modo a proporcionar uma experiência multissensorial. Os autores observam que esse tipo de atmosfera exerce um impacto no comportamento das pessoas e deve ser considerado na concepção doambiente da loja.Assim, é possível usar estes sinais para diferenciar-se dos concorrentes e de suas categorias de produtos, que muitas vezes estão vinculados a um contexto particular de varejo.Asdecisões sobre como projetar uma atmosfera de loja envolvem múltiplos sinais, mas quais são os mais relevantes? 
Na prática, parece não haver consenso sobre quais sinais devem ser vistos como complementares aos visuais. Além disso, poucos insights são oferecidos sobre como introduzir sugestões multissensoriais para projetar uma atmosfera de loja que influencie positivamente as emoções e o comportamento dos compradores (Helmefalk \& Hultén, 2017). Os autores afirmam que os sinais não-visuais são mais poderosos no aumento do tempo gasto e nas compras, do que simplesmente adicionar outra informação visual às já existentes no ambiente da loja. O excesso de um estímulo pode causar uma sobrecarga sensorial, acarretando o risco de ambientes complexos e estressantes. Os efeitos dos sinais multissensoriais sobre as emoções do comprador e seu comportamento de compra, tem importantes implicações para a lucratividade do cliente a longo prazo, bem como para a imagem da loja.Dessa forma, torna-se mais fácil a construção de uma experiência no ponto de venda que encante o consumidor e influencie suas impressões sobre determinada marca.

\section{Lojas conceito: definições e características}

A internet mudou a maneira de consumir, e consequentemente, o planejamento dos espaços comerciais. A percepção de um indivíduonão depende somente de estímulosfísicos, mas também de estímulos propagados pelo meio ambiente e pelas informações veiculadas em larga escala. Com a quantidade de lojas similares, as escolhas serão definidas pela vontade de consumir experiências e produtos únicos. Sendo assim, investir em ambiente que ofereça experiências de compra inesquecíveis é o melhor caminho para de destacar em um mercado competitivo.

Kumar e Kim (2014) trazem a ideia de Loja-como-marca, onde esta é vista como a marca em si, com potencial para estabelecer uma relação emocional e racional com seus públicos. $O$ relacionamento racional se dá pelos processos comerciais de compra e venda, e o emocional é alcançado a partir do momento em que comprar resulta em uma experiência divertida e memorável para o cliente. Ao atingir relações racionais e emocionais, uma loja deixa de ser uma mera distribuidora de produtos para se tornar uma marca forte e diferenciada.

A implementação desta estratégia, concentra-se não somente em fatores que afetam os sentidos dos clientes, mas também na variedade de produtos dentro da loja. Se os clientes perceberem uma desconexão entre a mercadoria e a atmosfera da loja, poderão mudar para uma concorrente, resultando em perda de venda.Elementos como cor, layout e sinalização usados em uma loja, podem afetar as avaliações dos clientes, como percepção da qualidade da mercadoria e do serviço. O mesmo produto pode ser visto como de maior qualidade em uma loja de alto padrão do que em uma mais simples (Kumar \& Kim, 2014).

Se, anteriormente o que importava eram as questões visuais e estéticas, agora vivemos 0 momento em que são exploradas as dimensõessensíveis dos objetos. A marca se expande através dos cinco sentidos, para proporcionar novas experiênciasdiferenciadas no ponto de venda. A intenção é melhorar a percepção do consumidor, e tambémcriar uma identidade da marca, que reforçe a sua impressão de qualidade, evoluindo da racionalidade funcional para a experiência sensorial.

As lojas-conceito ou conceptstore, surgem como estratégiapara fortalecer a relação entre consumidores e marcas e como ferramenta de estímulo à experiência e ao consumo. A conceptstoreaproxima as pessoas dos valores simbólicosda marca. O projeto destas lojas explora referenciais semióticos com alto poder de sensibilizaçãodo seu público-alvo, desde macroelementos como o tema do ponto de venda, até microelementos como cores e texturas da arquitetura comercial e produtos exclusivos comercializados. Estes espaços envolvem 0 consumidor em um espaçosedutor, oferecendo-Ihes momentos de fantasia em um ambiente cuja atmosfera remeta a muito mais que a simples aquisição de uma mercadoria.

As conceptstore possibilitam a materialização e a concretização da essência da marca através da criação de um ambiente envolvido pela características de identidade e expressividade marcária que definem o seu posicionamento e sãoresponsáveis por associações mentais que colaboram para a construção de sentido. Através destes espaços as marcas conseguem maior conexão e interatividade com as pessoas. Isso se mostra importante 
em um momento de maior competitividade, pois desse jeito elas conseguem, através de conexões que vãoalém do trivial, criar as experiências e sensações queimpressionam os consumidores.

\section{Design da Informação: definições}

Desde a sua origem até os dias atuais o conceito de design passou por várias transformações. Esse processo se intensifica ainda mais a partir do século XX, devido aos avançostecnológicos que possibilitaram a configuração de diferentes tipos de produtos. Atualmente, o design envolve a produçãonãosó de objetos materiais físicos, mas também de interfaces gráficodigitais que trabalham para a construção de experiências relevantes entre as marcas e seus usuários (Quintão \& Triska, 2013).

O Design da Informação desenvolve a interface entre o meio e a mensagem, faz a ligação entre dois pontos que formam um todo maior, seja na área gráfica, seja nos aspectos sensoriais que se deseja transmitir. Os autoresdestacamsuaextensão, ao apresentar algumas de suas possíveisáreas de atuação: projeto de interfaces, imagens médicas, diagramas e manuais, mapas e planos de orientação digitais, design de informação para crianças, design de informação para televisão, gerenciamento de informações, entre outros. Aesses associamos também o estabelecimento e construção da identidade de uma marca.

Serrasqueiro e Domiciano (2017) afirmam que o Design de Informação tem compromisso com a clareza e entendimento das mensagens e para mante-lo objetiva analisar, planejar, apresentar e entender seu conteúdo, sua linguagem e sua forma, assim como qualquer atividade do design que busque eficiência em sua relação com o usuário. Esta compreensão é fator decisivo na análise e construção de sistemas de informação, assim como a preocupação com o acesso a ela. De acordo com as autoras é um termo amplo que discute abordagens que tratam da análise e percepção da informação. Prioriza a atenção às pessoas quando usam algum artefato e suas interfaces, sejam elas gráficas ou digitais. Tudo isso considerando as necessidades e exigências na compreensão do conteúdo a ser transmitido.

Em um momento em que somos sobrecarregados por uma grande quantidade de dispositivos cada vez mais sofisticados, o design da informação faciita o gerenciamento de todas as informações disponíveis. Horn (2000), fala que essa sobrecarga nos faz sentir "inoperantes no ciberespaço". Sendo que não precisamos de mais informação, mas da capacidade de apresentar a informação certa às pessoas certas, no momento certo de forma eficaz e eficiente.

De forma geral os autores concordam que esse campo de estudo diz respeito à disponibilização de informações, com clareza e objetividade, levando-se em consideração as pessoas a quem se destinam. O seu principal objetivo é a compreensão do que será comunicado, o que garantirá, ao final, sua correta interpretação pela maioria das pessoas dentro de uma audiência pretendida.

\section{Design de Identidade de Marca}

O mundo digital e o mundo real estão interconectados e o consumidor transita entre eles com desenvoltura, faz pesquisas e compras on-line e trocas na loja física. Neste cenáriodiferenciarse é questão de sobrevivência. Para engajá-lo é preciso mudar a forma de interação, dar um passo à frente das relações meramente comerciais e entregar para esse cliente uma experiência de loja concreta, única e envolvente.

A identidade da marca é tangível e apela aos sentidos, pode ser vista, tocada, agarrada, ouvida, observada e movida. A identidade é a sua expressão visual e verbal. Dá apoio, expressão, comunicação, sintetiza e visualiza a marca. Aumenta a conscientização e constrói empresas. Os melhores sistemas de identidade de marca são memoráveis, autênticos, significativos, diferenciados, sustentáveis, flexíveis e agregam valor. (Wheeler, 2012, p. 14).

Cullen apud Wheeler (2012) afirma que o design desempenha um papel essencial na criação e construção de marcas. Ele diferencia e incorpora os elementos intangíveis - emoção, 
contexto e essência, que mais importam para os consumidores. A autora afirma que a identidade de marca deve ser de fácil lembrança e reconhecimento imediato, desencadeando associações positivas e possibilitando a sua percepção por meio da integração do significado e da diferenciação visual.

Somos diariamente expostos a uma quantidade enorme de mensagens visuais, estamos cercados por marcas que se manifestam em nossas vidas de várias formas: ao abrir uma embalagem, dentro dageladeira ou no supermercado. E, em todos os exemplos citados um designer imaginou a melhor maneira de traduzir essa mensagem, para gerar reconhecimento e despertar o desejo de adquirir a marca (Wheeler, 2012).

O Design de Identidade de Marca ajuda nos processos de comunicação, favorecendo a empresa no seu mercado de atuação. Ao ser reconhecido ele promove a fidelização e apresenta um ponto de vista único, que sintetiza todo o posicionamento da marca que representa. Logo, ao se investir num programa sólido de Identidade de Marcafacilitamos o processo de compra para o consumidor pelo reconhecimento de uma imagem diferenciada e tornamos mais fácil a construção do brandequity, ou seja do valor de sua marca. Quanto mais forte é esta identidade, mais ela aumenta a fidelidade dos clientes.

Wheeler (2012) acrescenta que a identidade da marca é capaz de mostrar que tipo de organização você é, garantir ao público que você é realmente o que diz ser, conectar sua empresa a imagens e ideias, ser o fio condutor para construir patrimônio ao longo do tempo e proporcionar consistência nos canais de comunicação. Ou seja, é capaz de agregar vantagem competitiva à empresa, demonstrando claramente as suas características, valores e atributos. A autora conclui que uma boa Identidade é capaz de fazer as pessoas agirem, mudar sua mentalidade e enviarmensagens coerentes aos seus públicos, tangibilizando a marca em seus diversos aspectos - visuais, verbais, aromáticos, gustativos e táteis.

\section{Design da Informação e Design de Identidade na construção de espaços sensoriais da marca}

Os ambientes comerciais que propiciam aos seus clientes experiênciasagradáveis, exploramsensaçõesque resultam de um conjunto de elementos inseridos no interior da loja, como também em qualquer outro ponto de contato que o cliente tenha com a marca. Promover experiências diferenciadas tem sido uma das melhores táticas usadas pelas empresas para estar perto de seu cliente envolvendo-o totalmente para conquistar sua confiança e fidelidade (Scarpin \& Gouveia, 2014). Essas estratégias, em geral, acontecem no ponto de venda e tentam desenvolver relações baseadas em estímulos sensoriais diferenciadores, para produzir experiências singulares e duradouras. Nele identificamos a principais características de uma marca transmitidas por fatores tangíveis e intangíveis, que juntos podem nos impressionar de maneira positiva.

Para Silva (2010) precisamos entender a amplitude dos sentidos para facilitar o reconhecimento de uma marca em seu ambiente de consumo e consequentemente criar interações mais inteligentes com o consumidor. Através das ligações sensoriais podemos desenvolver relações que influenciam a percepção da marca pelos consumidores. Logo, elas precisam sair do foco bidimensional (visão e audição) para englobar todos os sentidos e estabelecer as estratégias eficientes e modernas. Conscientes disso, muitas marcas investem em espaços que permitam ao consumidor vivenciar uma forma de contato diferenciada. E, são as conceptstore que promovem esta vivência aos consumidores, através do estímulo dos sentidos.

Podemos falar que existem pontos de contato entre o design de informação e o design de identidade, pois são, as duas, disciplinas que trabalham com a transmissão de informaçõesestratégicas relacionadas aos conceitos da marca e com a construção de significados que devem ser percebidos em toda e qualquer relação que se tenha com ela.

O Design da Informação utiliza osprincípios do design na busca da informaçãoacessível, que passa pelo reconhecimento das características da marca, suas simbologias e elementos sensoriais, agindo como um tradutor que facilita a compreensão das mensagens 
transmitidas.Seu objetivo é proporcionar às pessoas experiências agradáveis pela estimulação dos sentidos, construindo uma ponte com os atributos e conceitos da marca, para que seja possível diferenciá-la dentre as concorrentes.

Por sua vez o Design de Identidade da Marca trabalha com os elementos de linguagem visual, paleta de cores, imagens, tipografia e os sensoriais, que devem ser desenhados com o objetivo de impulsioná-la, contribuindo para unificar e diferenciar o programa como um todo. Eles devem ser utilizados de maneira clara e consistente para construir e comunicar a sua personalidade, levando em consideração todos os pontos de contato: design de produto, design de loja, arquitetura, mensagens e propagandas. Uma marca deve sempre surpreender e agradar seus clientes. O bom Design de Identidade de Marca é aquele que funciona, através de produtos e serviços, pela união de conceitos de comportamento, ações e comunicações adequados.

Diante disso, o ambiente da loja assume o papel importante, pois ajuda a influenciar as pessoas em suas avaliações de caráter cognitivo, como a percepção de valor e de qualidade. Portanto, é correto afirmar que os elementos de design de uma loja de varejo, quando bem planejados, aumentarão as avaliações positivas dos clientes. Estes precisam ser cuidadosamente trabalhados para sugerir comportamentos e avaliações específicas dos consumidores e para atingiro mercado-alvo.Então, diante de um futuro cada vez maistecnológico será a experiência, promovida no ponto de venda, o grande diferencial para que as marcas se posicionem claramente perante seus concorrentes, e possibilitem escolhas assertivas aos seus clientes.

\section{Descrição e exemplo de uma loja conceito}

Para ilustrar as relações entre Design da Informação e Design de Identidade apresentamos a Farm, marca de moda feminina, criada em 1990, que tem na brasilidade um dos seus pilares e posiciona-se como tipicamente carioca: solar e cheia de energia. A Farm vende um estilo de vida inspirado no Rio de Janeiro, sua natureza e suas cores. Chamadas de "farmetes" as clientes possuem um perfil bem definido, são jovens entre 18 e 25 anos, universitárias, descoladas, antenadas e femininas; a típica garota carioca zona sul, que gosta de ir para a praia e não gosta de salto.

Nota-se a preocupação dessa empresa em construir uma identidade de marca, onde a loja tem um papel muito importante. Ao todo são 71 unidades, todas próprias, espalhadas por 22 estados dopaís. Dentre elas destacam-se as duas conceptstore: uma em Ipanema (fig. 1) e a outra no bairro paulista da Vila Madalena (fig. 2), elas que recebem em primeira mão os produtos de novas coleções, de coleções especiais ou mini-coleções exclusivas (que muitas vezes nem vão para outras lojas da marca). Elas funcionam como o centro de experimentações, vendendo o espírito da marca, e não apenas roupas e acessórios.

Figura 1: Aspectos da loja Farm Ipanema- RJ

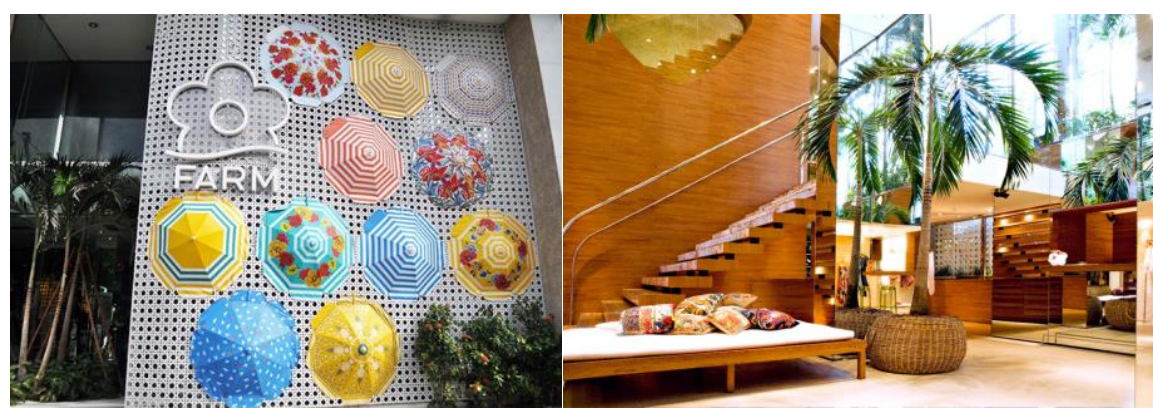

Anais do 9² Congresso Internacional de Design da Informação |CIDI 2019 
Figura 2: Aspectos da loja Farm da Vila Madalena - SP

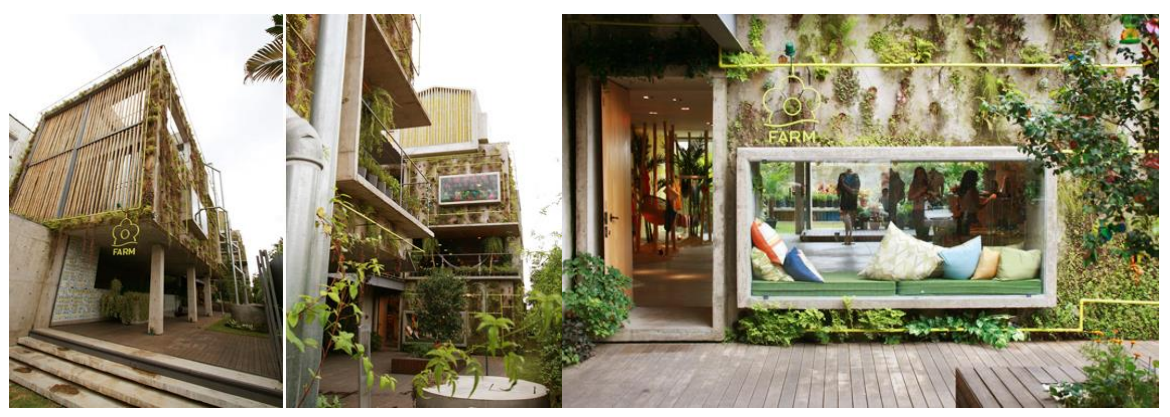

A arquitetura da Farm,de forma geral, obedece a um estilodecorativo que temdiversos elementos alinhados à estratégia de posicionamento, conferindo personalidade às lojas. $O$ projeto moderno é um grande diferencial, sua proposta verde e sustentável usa madeira de reflorestamento, possui sistema de tratamento e reutilização da água. No interior apresenta madeira nas paredes, os provadores tem piso de grama sintética e cortinas com estampas vegetais. Em algumas lojas existem plantas espalhadas pelo ambiente. Isso ajuda a construir uma atmosfera que remete ao natural, acolhedor e tranquilo. Também são amplas, espaçosas, arejadas e claras. A Farm desenvolveu um espaço para entrar, ficar e curtir, aproximando-se das consumidoras, para torná-las mais íntimas, não tratando-as somente como compradoras.

A empresa também se preocupa com outros elementos sensoriais que compõe sua identidade e são tão importantes quanto a arquitetura, o mobiliário ou os produtos. O aroma é exclusivo e a seleção musical direcionada às preferências das clientes. Em algumas unidades elas podem, inclusive, escolher a música que toca nos provadores. Tudo é feito para promover experiências emocionais que a aproxime ainda mais das clientes.

Além das ações direcionadas às lojas físicas a Farm também atua nas redes sociais, possuindo um departamento que cuida entre outras coisas, da loja virtual, do blog Adoro Farm, do Twiter e do e-mail Marketing. Também existe um aplicativo onde a usuária tem acesso ao conteúdo do blog e aolookbook da marca. Em breve serão disponibilizados tablets com imagens dos produtos das coleções.

Outro idéiainteressanteé conhecida como "mimos", oferecidos para as clientes a partir de parcerias com outras empresas. Já houveram diversas ações, como a distribuição de doces da marca Arcor no lançamento de uma linha especial no dia de São Cosme e Damião. No verão associou-se à cerveja Devassa, para disponibilizar geladeiras com os produtos nas lojas, essa foi repetida durante a Copa do Mundo, no desfile da coleção criada para o evento.

Com uma identidade de marca despojada,presente nasestampas coloridas e alegres, associadas a uma modelagem das roupas simples e solta (fig.3), a Farm faz o alinhamento das suas expressões, através de elementos que traduzem fielmente seus valores. Para tanto, faz uso de preceitos do Design de Identidade através de elementos simbólicosfacilmente reconhecíveis em seus produtos, projetos paisagísticos, itens decorativos e experiências sensoriais, que estabelecem um excelente canal de comunicação com as pessoas.

Figura 3:Exemplos de estampas e modelagens das roupasda Farm
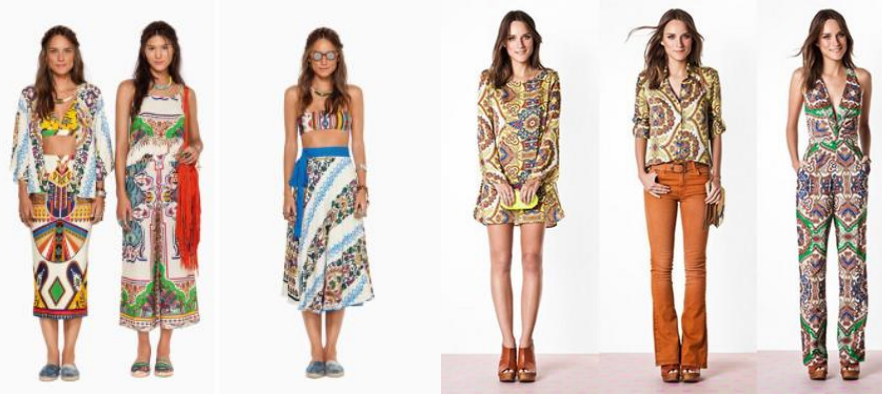

Anais do 9² Congresso Internacional de Design da Informação |CIDI 2019 
Já o Design da Informaçãofavorece a interface entre o meio e a mensagem,seja ela gráfiica ou sensorial, visando a informação mais clara e acessível, pelo reconhecimento das simbologias da marca: os elementos gráficos, as interfaces digitais ou as experiências vivenciadas dentro da loja, para sempre encantaras pessoas. Como já comentamos ambos visam construir uma ligação com os atributos da marca e suas manifestações nos pontos de venda, para destacá-la dos concorrentes. Juntos esses elementos ajudam a promover uma experiência singular, que as clientes reconhecerão como Farm.

\section{Considerações finais}

O Design Contemporâneo tem como principal referência as pessoas e seus estilos de vida. Busca traduzir o tempo atual através dos sistemas, objetos e serviços, para transitar em novos territórios e expandir fronteiras. Acontece em projetos complexos que exploram sensações e apresentam novas propostas que aprofundam as relações de função e uso, forma e conteúdo. $\mathrm{Na}$ contemporaneidade os espaços e lojas tradicionais se convertem em lojas conceituais, espaços coletivos ouconceptstores. Esses espaços apresentam os elementos de identidade que favorecem a comunicaçãocom o cliente e promovem experiências que sejam relevantes.

Tanto o Design da Informação quanto o Design de Identidade ajudam na construção da relação das empresas com seus públicos. Do primeiro destacamos o foco na objetividade e compreensão das mensagens, através do desenvolvimento da interface entre marca e público que considere suas necessidades e o conteúdo a ser transmitido. AFarm está em constante comunicação com as "farmetes", seja on-line no site, blog ou aplicativo, seja off-line em ações dentro das lojas, para comunicar os lançamentos de produtos especiais e novas coleções. A mensagem precisa ser simples e estar ligada à plataforma da marca, evitando a sobrecarga de informações.O objetivo é apresentar dados organizados, que serão convertidos em informação significativa. De nada vale uma mensagem que ninguém compreende. Umavez no contexto da marca, a mensagem pode ser de vários tipos: ilustração, design gráfico, arquitetura, entre outros.

O segundo facilita a identificação da marca em situações de mercado, utilizando para isto os seus elementos esseciais. Eles constroem umapersonalidade única e facilmente identificável nos pontos de contato. O estilo carioca, propagado pela Farm pode ser percebido em muitos detalhes, desde a iluminação eoaroma até asmúsicascuidadosamenteselecionadas.

Normalmente uma marca se relaciona com as pessoas através do seu logotipo, mas podemos ampliar esse leque trabalhando o tato, os aromas e os sabores. AFarmtrabalha com parceiros para entregar para as suas admiradoras a sua experiência de marca, em eventos públicos ou dentro das suas lojas.

O Design de Identidade aumenta o valor percebido da marca através de sua imagem consistente e diferenciada, e pode ser um fator decisivo no momento da escolha por uma ou outra. A marca estudada investe em novidades e ações nas lojas, para que as clientes transitem livremente pelo seu universo conceituale vivam momentos memoráveis onde o valor tangível do produtoé facilmente superado pelas sensações vividas dentro do seu território.

Estamos numa era em que para ter sucesso uma marca precisacompreender as necessidades dos clientes. Em um cenário competitivo, ter uma plataforma multissensorial que se aproxime do consumidor é de grande valor. É preciso entender que, independentedo segmento de atuação, a experiência é uma vantagem fundamental para obter destaque no mercado.Cada vez mais as lojas físicas serão espaços de imersão e interação com a marca. Nesse sentido o design, através das conceptstore, institui uma relação com as pessoas que une o utilitário e a essência da marca, traduzida em um espaço personalizado e reconhecível por elas. 


\section{Agradecimento}

O presente trabalho é parte das atividades do projeto DINTER-CAPES (Edital 012/2016 processo 04206/2016) UFMA/UNESP e foi realizado com o apoio da Fundação de Amparo à Pequisa e ao Desenvolvimento Científico e Tecnológico do Maranhão (FAPEMA) e Coordenação de Aperfeiçoamento de Pessoal de Nível Superior - Brasil (CAPES).

\section{Referências}

Helmefalk, M.,\& Hultén, B. (2017). Multi-sensory congruent cues in designing retail store atmosphere: Effects on shoppers' emotions and purchase behavior. Journal of Retailing and Consumer Services, Elsevier. v. 38, pp. 1-11. set.

Horn, R. E. (2000). Information design: emergence of a new profession. In: JACOBSON, Robert (ed.). Information design. Cambridge (MA): The MIT Press. 2000. Disponível em: http://steinhardtapps.es.its.nyu.edu/create/courses/2015/reading/Horn.pdf .Acesso em 30 jun. 2019.

Kumar, A., \& Kim, Y. (2014). The storeasabrand strategy: The effect of store environment on customer responses. Journal of Retailing and Consumer Services. Elsevier. v. 21, pp. 685-695.

Kotler, P. (1973). Atmospherics as a marketing tool. Journal of Retailing, 49(4), pp. 48-64.

Lipovetsky, G. (2016). Da leveza: Para a civilização do ligeiro. Lisboa: Edições 70.

Plascak, N. (2008). A Experiência sensorial da marca pós-moderna. In: Congresso Brasileiro de Ciências da Comunicação, XXXI, 2008, Natal. Disponível em: http://www.intercom.org.br/papers/nacionais/2008/resumos/R3-1153-1. Acesso em: 02 abr. 2019.

Quintão, F. S., \& Triska, R. (2013). Design de informação em interfaces digitais: origens, definições e fundamentos. Revista Brasileira de Design da Informação, 10(2), pp. 105 118.

Santos, A. (2018). Selecão Do Método De Pesquisa: guia para pós-graduandos em design e áreas afins. Curitiba: Insight.

Scarpin, T., \& Gouveia, A. L. (2014). Características de um Ambiente Comercial de Sucesso Pelo Olhar do Design Emocional.Revista UniCuritiba, 1(14), pp. 239 - 318.

Serrasqueiro, V. B., \& Domiciano, C. L. C. (2017). Design de informação para aprendizagem: uma análisemetodológica sob o olhar da inclusão.In: Congresso Internacional de Design da Informação, 8. Natal, data. 2017. Anais do 8ํㅡㄹ Congresso Internacional de Design da Informação. Natal.

Silva, A. L. B. da. (2010). Resenha: Brandsense: a marca multissensorial. Revista Signos do Consumo, 2(1)., pp. 132-135.

Wheeler, A. (2012). Design de Identidade da Marca: Guia essencial para toda a equipe de gestão de marcas. 3. ed. Porto Alegre: Bookman.

\section{Sobre os autores}

João Rocha Raposo, doutorando, UNESP / UFMA, Brasil<raposodoutorado@gmail.com> Mônica Cristina de Moura, PhD, UNESP, Brasil < monica.moura@unesp.br> 